\title{
Parents of adult children with schizophrenia dealt with societal objections in order to provide the necessary care
}

Milliken PJ, Northcott HC. Redefining parental identity: caregiving and schizophrenia. Qual Health Res 2003;13:100-13.

\section{QUESTION: What is the subjective and emotional experience of parental caregiving in schizophrenia?}

Design

Grounded theory.

Setting

A private setting chosen by participants, usually their homes, in British Columbia, Canada.

\section{Participants}

29 parents (mean age 62 y) from 19 middle or working class families, many of whom were retired. Both parents in 10 families, mothers in 6 families, and fathers in 3 were interviewed. The parents had 6 daughters (mean age $30 \mathrm{y}$ ) and 14 sons (mean age 32 y). 2 offspring had died 5 years before the study. Parents had been caregiving for an average of 11.5 years.

\section{Methods}

1.5-2 hour indepth audiotaped interviews. All couples but 1 were interviewed separately. Interviews were transcribed verbatim. Theoretical saturation occurred after 32 interviews (total of $53 \mathrm{~h}$ ).

\section{Main findings}

Parents of adult children with schizophrenia engaged in redefining their parental identity in order to adapt their caregiving to societal objections. This basic social process comprised 7 stages. Parent of a teen or young adult. Parents described their children's early development as normal, without any indication of impending mental illness. None was overly surprised when behaviour deteriorated during adolescence, and only 2 parents suspected that antisocial attributes were indicators of mental health problems. Eventually, all parents realised that their children's conduct was not normal. Becoming marginalised involved becoming alarmed and assuming responsibility for the child, but also encountering barriers. Children became excessively angry, depressed, anxious, isolated, or preoccupied, and family relationships suffered. Once a child was diagnosed, parents found that their influence was severely limited. Marginalised parents saw themselves as disenfranchised. The disenfranchised parent. Parents continuously met obstructions when they tried to intercede on their child's behalf. The stage was characterised as a miserable existence of maintaining vigilance, grieving alone, and grasping at straws. Embracing the collective. By connecting with others, parents learnt that they no longer faced mental illness alone. They communicated with each other and shared strategic approaches. The re-enfranchised parent. Parents regained their rights and responsibilities by taking on the "system" through volunteer work, advocating for patients with mental illness, and providing public education about schizophrenia. After many years and the achievement of some benefits for their children, parents began to reassess how they wished to spend their remaining years. Evaluating my life. Parents acknowledged realities and identified personal needs. They focused more on themselves or long ignored interests and moved towards mutual independence between themselves and their ill child. The emancipated parent.
Although the lives of all parents and their ill children improved, mutual independence was an unattainable goal. The end point was a hybrid identity combining (in varying degrees) the re-enfranchised parent and movement toward emancipation.

\section{Conclusion}

After feeling marginalised and disenfranchised, parents of adult children with schizophrenia adapted their parental care to societal objections through a basic social process involving 4 parental identities and 3 transitional states.

\section{COMMENTARY}

Milliken and Northcott examined the process of redefining parental identity among parents of adults diagnosed with schizophrenia. The findings are consistent with others that describe a slow process of recovery, with specific stages. ${ }^{1-3}$ The journey described in this study reflects changes throughout the years. This broader perspective is an addition to the literature, and gives hope through the positive description of some of the later phases.

As the sample was primarily drawn from 2 support agencies, it is not surprising that the later phases include embracing the collective and political action. Current findings may be most applicable to family members who tend to actively seek out such supports and activities. However, the support and opportunities for growth offered by such groups are clearly evidenced through the described process. It would be interesting to contrast this with the journey of those who do not belong to such organisations. Is it possible for families to heal and redefine their identity if they strike out alone?

Findings about the importance of collective healing for parents have clear policy implications and add to the literature regarding support agencies for families. ${ }^{4-5}$ Such agencies tend to be underfunded and are not always available. Resourcing such agencies may assist families who need support to continue involvement with their children. Nurses need to be sensitive to the varying needs at each stage of the process. Nurses are often involved with patients and families at the early stages of becoming marginalised and disenfranchised. Indeed, nurses' actions have the potential to add positively or negatively to these processes. Nurses need to be aware of the healing potential of the collective and inform families of these opportunities.

Cheryl Forchuk, RN, PhD Professor/Scientist University of Western Ontario/ Lawson Health Research Institute London Health Sciences Centre London, Ontario, Canada

1 Karp DA, Tanarugsachock V. Mental illness, caregiving, and emotion management. Qual Health Res 2000;10:6-25.

2 Kotcher M, Smith TE. Three phases of clozapine treatment and phase-specific issues for patients and families. Hosp

Rose L, Mallinson RK, Walton-Moss B. A grounded theory of mental illness. West I Nurs Res 2002:24:516-36.

4 Dixon L, Lyles A, Scott J, et al. Services to families of adults with schizophrenia: from treatment recommendations to issemination. Psychiatr Serv 1999;50:233-8.

5 Rose LE. Families of psychiatric patients: a critical review and future research directions. Arch Psychiatr Nurs 1996;10:67-76. 